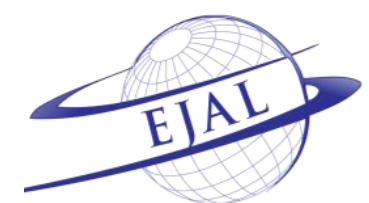

Eurasian Journal of Applied Linguistics, 5(3), 461-471
Available online at www.ejal.eu

http://dx.doi.org/10.32601/ejal.651339
EJAL

Eurasian Journal of Applied Linguistics

\title{
Using Contrastive Terminology Analysis in Teaching a Foreign Language Chunxiang $\mathrm{Wu}$ a $1 \mathbb{C}$, Jennifer Baccanello a $2 \mathbb{C}$
}

\author{
a Department of Cultural Communication, Shanghai International Studies University, China
}

Received 02 February 2019 | Received in revised form 15 May 2019 | Accepted 16 May 2019

\section{APA Citation:}

Wu, C. \& Baccanello, J. (2019). Using contrastive terminology analysis in teaching a foreign language. Eurasian Journal of Applied Linguistics, 5(3), 461-471. Doi: 10.32601/ejal.651339

\begin{abstract}
This study focuses on teaching Chinese for Special Purposes (CSP) and explores how terminology used in Chinese commercial contracts can be taught using a contrastive terminology analysis. Firstly, we outline the contextual differences that exist between commercial contracts drafted in Chinese and those drafted in English. Secondly, we describe the method of contrastive semantic analysis and show how it can be paired with corpus linguistics in order to help L2 Chinese learners acquire vocabulary used in Business Chinese, focusing specifically on Chinese commercial contracts. Thirdly, we shall explore the semantic equivalence between lexical items of different languages. Lastly, we present a semantic analysis of terminology found in Chinese and English commercial contracts. We hope that the theoretical framework presented in this paper will be of use to teachers of Chinese for Special Purposes.
\end{abstract}

(C) 2019 EJAL \& the Authors. Published by Eurasian Journal of Applied Linguistics (EJAL). This is an open-access article distributed under the terms and conditions of the Creative Commons Attribution license (CC BY-NC-ND) (http://creativecommons.org/licenses/by-nc-nd/4.0/).

Keywords: contract; contract law; semantic equivalence; contrastive linguistics; Chinese for Special Purposes (CSP)

\section{Introduction}

Following China's evolution into a market economy and given that China and the west are closely intertwined in terms of international business, it is natural for us to have the need to reflect on differences and similarities in our rules and customs, our law, and our different languages. The commercial contract, a crucial document for international deals and transactions, undoubtedly plays a key role in intercultural communication in business. For those involved in international business, we consider it useful to see communication in one language not merely as a self-producing artefact that exists within a closed system, but rather to consider communication as a process that can be influenced by a range of factors including intercultural contacts as well as societal and cultural changes. We can take the common law system as an example of this very occurrence, where judgments in the English legal system and interpretations of law can have important consequences for other common law

\footnotetext{
1 shdwchx@126.com

2 Corresponding author.

E-mail address: jbaccanello@gmail.com
} 
jurisdictions such as Australia. Another example of how different societies influence each other is in the case of developing legal systems. For example, in the early 20 th century, China adopted a civil law system partly based on European legal codes. Since this major milestone in Chinese legal history, we have seen a step away from traditional Chinese notions of how laws should be implemented in society. China's legal system has continued to evolve and modernize since its adoption of the German legal code in the early 20th century. Examination of key concepts in commercial contracts and definitions of these concepts is an important goal for international business communication. This paper seeks to undertake a contrastive analysis of terms in contracts in different legal systems, namely, the Chinese legal system and the English legal system.

The analysis of terminology used in commercial contracts is particularly useful for L2 learners of languages for special purposes as these learners are participants of rapidly evolving international business relations. Chinese and English are chosen for the analysis as they are widely used in international business. The legal system of the People's Republic of China is therefore the background of our study on Chinese language, while the English legal system is the background of our study on English language given that the Anglo-Saxon legal system has a lengthy legal history and has become a model for many other common law systems.

This research aims to shed light on the different parts of the semantic analysis of commercial contract terminology that must be considered. The research has three main objectives: to investigate the similarities and differences in the legal context dealing with terminology in commercial contracts in Chinese and English, to highlight the problem of equivalence in dealing with legal terminology, and to encourage and promote corpus linguistics as a useful tool for L2 learners.

In this research, we deal with terms by giving several examples of common terms found in contracts and their usage. By describing the usage of these terms in different legal systems and analysing their most important features, we pay special attention to semantics and corpus linguistics. This kind of analysis is important for the learning process and application of terminology found in commercial contracts. The method of this study is a combination of descriptive and contrastive methods so that we can describe and compare semantic features of Chinese and English terminology in commercial contracts.

\section{Contrastive semantic analysis and corpus linguistics}

\subsection{Contrastive semantic analysis}

Contrastive semantic analysis is a useful way of understanding the evolution of legal terminology. It can be described as the process of looking at two or more languages and analysing the languages at a range of different levels. For example, one could look at the levels of the phrase, clause, sentence and paragraph, or rather, the writing as a whole. 
Contrastive research has been carried out extensively by terminologists. For example, Cao (2016) has written extensively on the Chinese language used in the context of law, making comparisons with the English language. Cao (2016) mentions a general term she refers to as 'Chinese linguistic uncertainty' when describing vagueness, generality and ambiguity in the Chinese language, and in doing so, provides examples of how Chinese language can have structural or syntactical ambiguity. Mattila's (2006) work Comparative Legal Linguistics is an in-depth investigation on topics such as characteristics of legal language, legal terminology, and legal linguistics. However, non-European languages such as Chinese were not considered. Therefore, this current study aims to add to the current comparative literature in the field of legal linguistics by exploring the Chinese language. Importantly for L2 learners, contrastive semantics can help learners understand the differences between languages and discover particular characteristics that may be unique to a given language. These can serve as useful tips for foreign language

teaching, as teaching new lexical items to students ought to go beyond merely showing a rough equivalent in the student's native language, but should also include the teaching of features that are idiosyncratic, as well as those features that are universal (Makino, 1974). In the mid-to-late 20th century, contrastive analysis was used following the emergence of linguistics theories such as Ferdinand de Saussure's structural linguistic theory. Later, J. B. Watson, who worked on the behaviorist theories of second language acquisition, was concerned with interference and its role in linguistics. Accordingly, contrastive analysis was also used to provide insight on interference in language learning. As emerging fields such as computer assisted linguistics evolve, contrastive analysis may begin to resume its once important role. Scholars such as Breeze (2017), McEnery and Xiao (2011), Bennet (2010), Sinclair (2004), Aston (2001), and Johns and King (1991) have discussed how data-driven learning exploiting the use of corpora can be used for foreign language teaching purposes, and studies such as those carried out by Mattila (2006), Sandrini (1996) and Kocbek (2006) could be broadened so as to make further cross-linguistic comparisons.

\subsection{The role of corpus linguistics in contrastive semantic analysis}

A range of studies in different professional fields have commented on the use and value that corpora has in structured education (see Hafner \& Candlin, 2007). While corpora are useful for students learning about a language, Breeze (2017, p. 2) comments that corpora are "even more important in the area of languages for specific purposes". Corpus linguistics may be considered as a methodology, in which the researcher can closely examine the frequency at which linguistic elements occur. In contrastive semantic analysis, corpora could therefore be used to compare information in frequency lists across two or more languages. For example, at the semantic level, we may be interested in looking at how near synonyms differ from each other. Whilst this study does not include the use of a specialized corpora for teaching Business Chinese to L2 Chinese learners, we can see from the semantic analysis below that by building specialised corpora for the teaching of languages for special purposes, we 
would be able to closely analyse the use of terminology in particular contexts and make cross-linguistic comparisons that could reveal important differences in the implied meaning and usage of terminology.

\section{Comparing contextual differences of commercial contracts}

For this study, it is important to note that one cannot perform a comprehensive semantic analysis without having an understanding of the contextual differences of the terminology. Accordingly, this section first explores the similarities and differences that exist between the background in which commercial contracts drafted in Chinese in China and commercial contracts drafted in English in the UK. This therefore involves a discussion on the legal system in both countries. One of the main pieces of legislation governing Chinese commercial contracts is the Chinese Contract Law (CCL), while commercial contracts in the UK are governed by a body of law, including both case law and the Sale and Supply of Goods Act.

The most widely held notion of contractual formation is that there is an offer made by one party to another, and that there is acceptance of that offer. In conforming to this standard found in both common and civil law systems, the CCL also adheres to this notion, as stipulated in Article of the CCL. While the word hetong is often used in China to describe a contract, for many centuries prior, the term qiyue (agreement) was in fact used. Qiyue is typically referred to a legal relationship between parties and involving a legal obligation.3

While rules governing qiyue differed from dynasty to dynasty in China, there were three common characteristics (Zhang, 2006, p. 27):

First of all, most of the rules in their formality were customs or common usages complied as norms. Secondly, the rules were patriarchal in nature and focused primarily on obligations without specifying rights. (...) Thirdly, the punishment for breach of agreement or violation of obligation was harsh, and mostly was punitive as provided in the penal law.

In ancient times in China, moral standards were of key importance in regard to enforcing contractual obligations, and Confucian philosophers played a key role in advocating morality and virtue, which can be seen in the Confucian doctrine: "a promise, once made, shall worth thousands ounces of gold."

In recent Chinese history, we can see a move away from traditional reasoning towards a reliance on civil law tradition. For example, the first draft of China's Civil Code was mainly based on the German and Japanese law models. In China, several features characterise the legal contract. Firstly, a contract is a 'civil legal act' performed by natural persons, legal persons and other organisations of equal status. Secondly, the purpose of a contract is to create, change and terminate a relationship concerning civil rights and obligations. Finally, a contract is an agreement expressing 
the will of two or more parties. Unlike English contract law however, Chinese contract law does not require a contract to be supported by any consideration, that is, some sort of burden or obligation in the contract owed by one party to the other. In common law, consideration is an essential element, as without there being any consideration, the so-called 'contract' would be treated merely as a gift. In comparison, Chinese contract law requires the mutual assent of the parties to the contract, and "it is essential that the parties have a meeting of minds through the negotiations on a voluntary basis" (Zhang, 2006, p. 91). Another important element in contract law is that there is an 'offer' to enter into a contract, as stipulated in Article 14 of the CCL: "a manifestation of an intent showing the desire to enter into a contract with others." Article 14 of the CCL also sets out that two particular requirements need to be met in order to constitute an offer: (a) the contents shall be concrete and definite and (b) the offeror shall be bound by his manifestation of the intent upon acceptance by an offeree.

English law, as previously mentioned, consists of statutory law, common law, and rules of equity. English contract law also emphasises the autonomy of the parties, a principle that evolves from the western idea of a free market economy and that parties should be free to determine their own interests, whereby a contract is a voluntary agreement between two parties enforceable in law. A contract is formed after one party makes an offer and another party accepts the offer by communicating it to the other party or performing the terms of the offer. Under English contract law, the essential elements of a contract include the following four key elements: offer, acceptance, consideration, and intent to create legal relations.

A notable difference between the contract law in China and that in the UK is that in the UK, contract law is largely derived from common law, with the law evolving and being revised through court decisions. On the other hand, in China, contract law is found in legislation.

\section{Semantic equivalence}

It is important to consider the concept of semantic equivalence given that L2 learners dealing with commercial contracts may need to know what the equivalent word of one language is in another. However, even the task of describing and defining equivalence has been controversial, and has produced an extensive amount of literature on the topic. While strategies for successfully achieving terminological equivalence in legal translation go beyond the scope of this study, we note that various strategies have been utilized, including using "a semantic reference scheme, componential analysis, and the principle of productivity and economy" (Cheng \& Sin, 2008, p. 33). Given that legal systems, such as the Chinese and English legal systems, are inherently different, it may be more appropriate, as Matulewska (2016, p. 163) describes, to speak of "quasi-synonymous terms" instead of synonymous terms, since absolute synonyms "that would have the same meanings and would be interchangeable in all communicative (situational) and syntactic contexts" are almost 
nonexistent. As Juodinytė-Kuznetsova (2015, p. 64) describes, "[a] more appropriate way is to choose the closest natural equivalent that is capable of providing the legal sense of the source term and leads to the favourable outcome". Accordingly, L2 Chinese learners need to take into account both the legal meaning of a term as well as the role that the term has in communication, and keep in mind that legal implications, whilst they may be similar, may still have important distinctions in different legal systems. Considering the legal term consideration used in the English legal system, which refers to the exchange of something of value for something else, we have already noted that it is not a requirement in Chinese contracts. Therefore, it is impossible to produce a semantically equivalent Chinese word for the term consideration in most cases. However, we can see the term duijia (对价), meaning consideration, used in the Chinese context in specific cases. For example, in maritime insurance contracts, the term duijia is used to refer to the premium paid by the insured party and the promise by the insurer to compensate the insured party for any liable damage suffered.

Having given a basic introduction to contextual differences in contract law in China and the UK and discussed the use of contrastive semantic analysis and corpus linguistics as well as the concept of semantic equivalence, we can now analyse and contrast terminology found in Chinese and English commercial contracts. For the purposes of this paper, we have chosen to focus on three terms commonly found in commercial contracts: contract, agreement, and good faith. These terms were chosen because despite their commonality, there exist important semantic differences when directly translated from English to Chinese and vice versa, and these differences can have significant consequences in the legal setting.

\section{Results and Discussion}

Contracts can come in a variety of forms, some governing simple transactions and others governing more complex transactions. To be able to accurately translate the terms in a contract, one must not only have adequate linguistic knowledge, but must also be ready to handle the differences between different cultures and societies and different legal systems. By undertaking a close analysis of specific terms used in contracts, we are able to solve problems that occur in translation and more accurately understand the meaning of specific terms and how they are used.

To undertake a contrastive analysis of contractual terms in Chinese and English, the definitions of the terms are given and comparisons have been made between the Chinese and English usage. To carry out this analysis, we consulted online English Living Dictionaries developed by Oxford University Press, Elliott \& Quinn's Contract Law (7th ed.) textbook, as well as legislation from China including the 1930 Civil Code, the 1986 Civil Code, and the 1999 Contract Law. The analysis was undertaken by four reviewers (including the authors) who each worked independently before discussing their opinions as a group. This process required the reviewers who are native Chinese speakers to analyse the terminology (contract, agreement, and good 
faith) according to their usage in the Chinese context, and the reviewers who are native English speakers to analyse the terminology according to their usage in the English context. Each reviewer consulted online dictionaries and the abovementioned texts in order to analyse semantic characteristics of the terminology and make comparisons between Chinese and English. Finally, the reviewers had a group discussion in order to contrast the terminology.

\subsection{Case study 1: Contract / hetong (合同)}

In the English language, the word contract is defined as "a written or spoken agreement, especially one concerning employment, sales, or tenancy, that is intended to be enforceable by law" (Oxford University Press, 2019). More specifically, there are five basic elements that form a contract: an agreement (between parties), an intention (to be legally bound by that agreement), certainty (of the terms of the agreement), capacity (of the parties to contract), and consideration (provided by each party) (Elliott \& Quinn, 2009, p. 9). The word contract is of Latin origin, derived from the word contractus meaning an agreement. The equivalent of contract in Chinese is hetong, and this term was originally referred to as qiyue (agreement), as seen in the 1930 Civil Code. Similar to English law, "[a] Qi Yue (agreement), once made, commonly implied a legal relationship under which an obligation was created" (Zhang, 2006, p. 26) despite the code was not actually giving a definition of qiyue. However, the 1930 Civil Code was not the first mention of qiyue in Chinese history. As Zhang (2006) notes, there were three common characteristics through Chinese history regarding qiyue, summarized as follows: most rules regarding qiyue were treated as norms, rules mainly highlighted obligations and did not describe rights as such, and punitive punishment was generally laid out to deal with a breach of a qiyue in a harsh manner. In fact, the qiyue had a strong emphasis on the moral standards of parties to the qiyue, influenced by the ideas of Confucian philosophers. By 1986, the term for 'contract' had been clearly defined in China's 1986 Civil Code, with Article 85 defining it as an agreement that establishes, modifies and terminates civil relations between parties to the contract. Article 2 of the 1999 Contract Law then put forward a definition of the contract, describing it as an agreement that establishes, modifies and terminates the relations of civil rights and obligations between natural persons, legal persons or other organisations of equal status. Comparing English contract law with Chinese contract law, there is a notable difference. English contract law considers a contract to be an act or promise by one party to another party for consideration. This concept of promise is central to the definition of English contract law, whereas in China, the emphasis is on what would create an agreement between parties and how that agreement would be enforced. This analysis shows that although contract and hetong can be considered equivalents, they do possess certain semantic differences that could have important implications. 


\subsection{Case study 2: Agreement / xieyi (协议) / qiyue (契约)}

In English law, it is important to note that while all contracts are agreements, not all agreements are contracts. We can describe the contract therefore as a formal written document, but it may also be made orally. An agreement is a more general term, and may also refer to either a written or oral agreement. An agreement may be described as an arrangement or understanding between parties, without necessarily being legally binding and enforceable in a court of law. In contrast, a contract implies an arrangement or understanding between parties, but the contents of the contact are in fact legally binding and enforceable in a court of law. The situation is similar in Chinese, where although all hetong are xieyi, not all xieyi are hetong; only those xieyi that possess the elements needed to establish an enforceable contract can be considered to be hetong. Accordingly, although the concepts embodied by the terms xieyi and hetong are similar, the scope of their usage is different and cannot always be interchanged. L2 Chinese learners will notice too that collocations of the two terms differ. For example, some common phrases using xieyi include: koutou xieyi 口头协议 (verbal agreement), dacheng xieyi 达成协议 (reach an agreement; come to an agreement) and sihui xieyi 撕毁协议 (tear up an agreement). Chinese has a semantically related term, qiyue, which can also be translated as 'contract' or 'agreement'. Similar to the word 'agreement' in English, qiyue may be construed widely to refer to a promise or series of promises, which are not necessarily legally binding. Alternatively, qiyue may be construed more narrowly to refer to a formal document made according to law. Qiyue may also refer to a 'covenant' or 'deed' in English, while 'xieyi' may refer to 'protocol' in English. From this analysis, we can see that an 'agreement' may be translated into Chinese as qiyue or xieyi, depending on the circumstances, and that qiyue can be translated as agreement, covenant or deed, while xieyi may be translated as agreement or protocol. We can also see that although the above-mentioned terms (agreement, xieyi and qiyue) are semantically related, the concepts that these terms refer to have their respective differences.

\subsection{Case study 3: Good faith / shanyi (善意)}

The term 'good faith' comes from the Latin phrase bona fides. In ancient Rome, the phrase bona fides was an obligation for both parties to adhere to and necessitated legal and religious consequences if it was violated (Adam, 2009). In the English legal system, good faith refers to the upholding of honesty and fairness. More specifically, in contract law, there is an implied covenant of good faith, which denotes that parties to a contract shall deal with each other honestly and fairly. The UK has gone so far as to adopt good faith as a general principle of law4. This is in contrast to the US legal system which has been less adverse to adopting good faith as a core concept of private law. Accordingly, an implied covenant of good faith and fair dealing was incorporated into the Uniform Commercial Code in Section 1-304 and later codified by the

4 See the case of Yam Seng Pte Ltd v Int Trade Corp Ltd where the High Court expressed a preference to adopt good faith as a general principle of law. 
American Law Institute as Section 205 of the Restatement (Second) of contracts (Dubroff, 2006). It is important to note that there is no universally accepted meaning of good faith, and that its meaning may differ depending on the type of contract and the overall commercial context. However, we can summarise a duty of good faith as entailing the following obligations: adhering to the spirit of the contract, observing reasonable commercial standards of dealing, being faithful to the agreed common purpose, acting consistently with the justified expectations of the other party, preventing action that frustrates the purpose of the agreement, requiring disclosure of all material facts to the other party, not knowingly lulling the other party into a false belief, and not proving false information upon which the other party will rely on (Garside et al., 2018). The term 'good faith' has an equivalent in Chinese with the term shanyi (善意). The courts have taken a strict view of the concept of good faith, where in the context of contract law, a contract will not be held to be enforceable if the principle of good faith has not been observed (Zhang, 2006, p. 70). Similar to the English understanding of good faith, in China it was first enunciated in the Civil Code where it was described as "honesty and credibility". The relevant law dealing with good faith in China is found in Article 6 of the Contract Law that states "parties to a contract shall observe the principle of honesty and credibility in exercising their rights and fulfilling their obligations". It has been claimed that this concept is rooted in Confucian tradition as it is a moral norm that has lasted throughout Chinese history and society (Zhang, 2006, p. 76). Similar to English law which does not seem to have a concrete definition of good faith, Contract Law in China has not provided a definition of the term either. However, we can gain an understanding of the Chinese interpretation of the term by looking at how Chinese scholars have criticised the American view, which considers good faith merely as "honesty in fact in the conduct or transaction concerned" (Section 1-201 (19) UCC). Chinese scholars believe that this interpretation of good faith does not adequately consider the interests of the parties or the need to balance the interest of the parties with the interests of society (Zhang, 2006, p. 76). As Zhang (2006) describes, good faith interpreted in the eyes of Confucianism covers more than just honesty, but faithfulness, trustworthiness, and even credibility, and involves an obligation to balance the interests between parties and society. Such ideas can be summed up neatly in the words of Confucius that “people could not live without credibility" ( $\min$ bu xin bu li - 民不信不立) (Zhang, 2006, p. 76). As we can see from the above analysis, there appears to be a greater emphasis in the Chinese context of moral values regarding good faith than in the English context where courts have been traditionally less willing to interfere with the autonomy of parties.

\section{Conclusion}

As can be seen from the analysis of the terms contract, agreement and good faith above, it is not always possible to produce legal equivalence between two or more languages. Factors affecting this possibility include whether or not the text has a legal effect in the target jurisdiction, and whether or not a certain term in the source 
language has the same legal implications in the target language. L2 Chinese learners dealing with commercial contracts and seeking to understand other legal texts ought to keep in mind that such texts typically have a definite purpose. Accordingly, when looking to find or confirm the corresponding term in the L2, the functional equivalence of the word or phrase should be sought depending on the particular context, or rather, the illocutionary act or intended meaning of the text (Cheng \& Sin, 2008). Regarding the use of corpus in teaching languages for special purposes, both teachers and students could make use of relevant corpora in order to gain insight into semantic similarities and differences between terminologies across two or more languages. For example, non-native Chinese learners studying Legal Chinese can make use of online resources such as Beijing Language and Culture University's BCC corpus, in addition to online dictionaries. Online corpora often have the benefit of providing a collocation function so that students can gain insight into the context that a specific term is typically used in. Students can also refer to online resources specifically related to legal language such as Stanford University's China Guiding Cases Project, which provides text of China's leading cases and commentary. By adopting such methods, students are able to raise their awareness during the language learning process and avoid mistakes commonly made by L2 learners.

\section{References}

Adams, J. P. (2009). The Roman Concept of Fides. Retrieved from http://www.csun.edu/ hcfll004/fides.html

Aston, G. (Ed.). (2001). Learning with corpora. Houston: Athelstan.

Bennet, G. (2010). Using corpora in the language learning classroom: Corpus linguistics for teachers. Michigan: University of Michigan Press.

Breeze, R. (2017). Corpora and computation in teaching law and language. International Journal of Language \& Law, 6, 1-17. DOI: http://dx.doi.org/10.14762/jll.2017.001

Cao, D. (2016). Chinese law: a language perspective. New York: Routledge.

Cheng, L. \& Sin, K. (2008). Terminological equivalence in legal translation: A semiotic approach. Semiotica, 172, 33-45. DOI: http://dx.doi.org/10.1515/SEMI.2008.088

Dubroff, H. (2006). The implied covenant of good faith in contract interpretation and gapfilling: Reviling a revered relic. St. John's Law Review, 80(2), 559-620. Retrieved from https://scholarship.law.stjohns.edu/cgi/viewcontent.cgi?referer $=\&$ httpsredir $=1 \&$ article $=120$ $0 \&$ context=lawreview

Elliott, C. \& Quinn, F. (2009). Contract Law (7th ed.). UK: Pearson Education Limited.

Garside, K. J., Pigott, A. R., \& Bates, J. (2018). UK: The Basics: The Current Position On Good Faith. Retrieved from http://www.mondaq.com/uk/x/709832/Contract+Law/The+Basics+The+current+position+on +good+faith

Hafner, C. A., \& Candlin, C. N. (2007). Corpus tools as an affordance to learning in professional legal education. Journal of English for Academic Purposes, 6(4), 303-318.

Johns, T., \& King, P. (Eds.). (1991). Classroom concordancing. Birmingham: University of Birmingham. 
Juodinytè-Kuznetsova, K. (2015). Contrastive semantic analysis of contract law terms in studies of foreign language for specific purposes. Sustainable Multilingualism, 7, 58-72. DOI: http://dx.doi.org/10.7220/2335-2027.7.3

Kocbek, A. (2006). Language and culture in international legal communication. Managing Global Transitions, 4(3), 231-247. Retrieved from http://www.fm-kp.si/zalozba/ISSN/15816311/4_231-247.pdf.

Makino, S. (1974). Contrastive semantic analysis and teaching Japanese. The Journal of the Association of Teachers of Japanese, 9(1), 21-34.

Mattila, H.E.S. (2006). Comparative legal linguistics. Hampshire: Ashgate Publishing Limited.

Matulewska, A. (2016). Semantic relations between legal terms: A case study of the intralingual relation of synonymy. Studies in Logic, Grammar and Rhetoric, 45(1), 161-174. DOI: http://dx.doi.org/10.1515/slgr-2016-0022

McEnery, T., \& Xiao, R. (2010). What corpora can offer in language teaching and learning. In E. Hinkel (Ed.), Handbook of research in second language teaching and learning (pp. 364380). US: Routledge, Taylor \& Francis Group.

Oxford University Press. (2019). Definition of contract in English. Retrieved from https://en.oxforddictionaries.com/definition/contract

Sandrini, P. (1996). Comparative analysis of legal terms: Equivalence revisited. In Galinski, Ch., Schmitz, K. D. (Eds.). Terminology and Knowledge Engineering (pp. 342-351). Retrieved from http://homepage.uibk.ac.at/\%7Ec61302//publik/tke96.pdf

Sinclair, J. (Ed.). (2004). How to use corpora in language teaching. Amsterdam and Philadelphia: John Benjamins.

Yu, J. (俞江). (2003). “契约”与 “合同”之辨——以清代契约文书为出发点. (Difference between “Agreement" and “Contract”- Starting with Qing Dynasty Agreements). 中国社会科学 (Social Sciences in China), 6, 134-148. Retrieved from http://article.chinalawinfo.com:81/article_print.asp?articleid=38124

Zhang, J. (1999). Evolution of the Chinese legal civilization. China: University of Political Science and Law Press.

Zhang, M. (2006). Chinese contract law: Theory and practice. Leiden: Martinus Nijhoff Publishers.

\section{Copyrights}

Copyright for this article is retained by the author(s), with first publication rights granted to the Journal.

This is an open-access article distributed under the terms and conditions of the Creative Commons Attribution license (CC BY-NC-ND) (http://creativecommons.org/licenses/by-nc-nd/4.0/). 